\title{
Sources and Reactions to Stress in Brazilian Lawyers ${ }^{1}$
}

\author{
Maria de Fátima Antunes Alves Costa \\ Associação Brasileira de Ensino Universitário, Belford Roxo-RJ, Brazil \\ Maria Cristina Ferreira ${ }^{2}$ \\ Universidade Salgado de Oliveira, Rio de Janeiro-RJ, Brazil
}

\begin{abstract}
Job stress can negatively affect the health of employees. As such, the investigation of its characteristics in different professional categories is relevant. The aim in this study was to analyze the predictive power of seven stressors (decision latitude, psychological demands at work, physical demands at work, social support from colleagues, ergonomic stressors, relationships with clients, job insecurity) for job dissatisfaction, depression and psychosomatic problems in a sample of 702 Brazilian lawyers. The data were collected using a Brazilian version of the Job Content Questionnaire (JCQ). The results showed that decision latitude and social support were the main negative predictors of stress, while psychological demands and job insecurity were its main positive predictors. These results are discussed in the light of the demand-support-control model, which was used as a framework for the research.
\end{abstract}

Keywords: occupational stress, job satisfaction, depression, psychosomatic disorders

\section{Fontes e Reações de Estresse em Advogados Brasileiros}

\begin{abstract}
Resumo: O estresse ocupacional pode afetar negativamente a saúde do trabalhador, o que torna relevante a investigação de suas características em diferentes categorias profissionais. O presente estudo teve por objetivo analisar o poder preditivo de sete fontes de estresse (latitude de decisão, demandas psicológicas do trabalho, demandas físicas do trabalho, suporte social de colegas, estressores ergonômicos, relacionamento com clientes e insegurança no trabalho) na insatisfação no trabalho, na depressão e em problemas psicossomáticos, em uma amostra de 702 advogados brasileiros. A coleta de dados efetivou-se por meio de uma versão adaptada do Job Content Questionnaire (JCQ). Os resultados obtidos revelaram que a latitude de decisão e o suporte social constituíram-se nos principais preditores negativos do estresse, enquanto as demandas psicológicas e a insegurança no trabalho foram os seus principais preditores positivos. Tais resultados são discutidos a partir do modelo teórico de demanda-suporte-controle, que fundamentou a pesquisa.
\end{abstract}

Palavras-chave: stress ocupacional, satisfação no trabalho, depressão, distúrbios psicossomáticos

\section{Fuentes y Reacciones al Estrés en Abogados Brasileños}

\begin{abstract}
Resumen: El estrés laboral puede afectar negativamente la salud del trabajador y, por esto, es relevante investigar sus principales propiedades en diferentes categorías laborales. El objetivo del estudio fue analizar el poder predictivo de siete fuentes de estrés (latitud de la decisión, demandas psicológicas del trabajo, demandas físicas del trabajo, soporte social de colegas, motivos ergonómicos de estrés, relacionamiento con clientes e inseguridad en el trabajo) en la insatisfacción en el trabajo, en la depresión y en problemas psicosomáticos en una muestra de 702 abogados brasileños. La recolecta de dados fue mediante el Job Content Questionnaire (JCQ). Los resultados indicaron que la latitud de la decisión y el soporte social fueran los principales predictores negativos del estrés, mientras que las demandas psicológicas y la inseguridad en el trabajo fueran sus principales predictores positivos. Tales resultados son discutidos a partir del modelo de teórico de demandas-soportecontrol que fundamentó la investigación.
\end{abstract}

Palabras clave: estrés ocupacional, satisfacción en el trabajo, depresión, trastornos psicosomáticos

Research about work-related diseases started in the mid20th century and, since then, have contributed to understand different aspects related to the macro, meso and microorganizational contexts. Among these, occupational stress should be highlighted, in function of the severe problems this phenomenon can cause for occupational health. In that sense, when the work environment is perceived as negative

\footnotetext{
1 Paper derived from the primary author's master's thesis, under the advice of the secondary author and defended in the Graduate Program in Psychology at Universidade Salgado de Oliveira in 2010.

2 Correspondence address:

Maria Cristina Ferreira. Universidade Salgado de Oliveira. Rua Marechal Deodoro, 211, Bloco C. Centro. CEP: 24030-060. Niteroi-RJ, Brazil. E-mail: mcris@centroin.com.br
}

and the individuals seem to be incapable of attending to the excessive demands it provokes, they may end up experiencing a process of occupational stress, which tends to causes physical, psychological and behavioral consequences, besides affecting the professional performance (Cooper, Dewe, \& O'Driscoll, 2001).

Due to the serious effects this phenomenon provokes, experts from different areas have studied it for decades, as they are interested in clarifying its main causes and effects, as well as its characteristics in several professional categories. In this study, the legal profession is of particular interest, because it involves a series of very specific activities and tasks. Thus, these professionals are constantly exposed to various stressors in their daily professional life, which can 
entail joy, but also frustration and anxiety. In that sense, empirical evidence has shown that several factors associated with the legal profession end up compromising their mental health (Daicoff, 2008).

Brazilian studies on occupational stress in lawyers remain scarce, as research in this area has privileged the educational and health professions. Hence, this study intends to fill the information shortage about the Brazilian legal profession, specifically regarding the factors that influence these professionals' quality of life.

\section{Occupational Stress}

One of the occupation stress models most frequently used as a reference framework is the demand-control model, proposed by Karasek (1979). According to him, this construct is associated with a set of physical, emotional and social reactions, deriving from the types of relationships established between the level of psychological demands of work and the type of control the individual exerts. The psychological demand is related with the level of requirement the workers face in their job context, like pressure from third parties and the level of concentration demanded, among others. The control or decision latitude, in turn, involves the extent to which the individuals use their skills to perform their tasks, as well as their degree of decision authority (Karasek \& Theorell, 1990).

Karasek also highlights that the psychological demand and control are characterized as independent dimensions, both of which vary from low to high, which creates four possibilities of psychosocial experiences at work. These experiences can be represented on a graph in which the psychological demand is located on the abscissa axis and control on the ordinate axis, so that four quadrants can be established.

In the lower right quadrant, high-demand or high-strain work is located, which is characterized by a high demand and low control and generally arouses psychological reactions like fatigue, anxiety and depression. These reactions usually appear more frequently in activities that do not foresee the existence of interruptions capable of minimizing the tension they provoke. The upper right quadrant contains active work, associated with high demand and high control. Therefore, as a result of this type of work, individuals can get motivated to develop new types of behaviors, even if this can also lead them to emotional exhaustion. Thus, for example, management functions come with high demand levels. In addition, managers frequently need to use complex skills and possess great control or decision power and autonomy towards the established demands, which generally enhances their motivation.

Passive work is located in the lower left quadrant and is characterized by low demand and low control. Examples are secretary and reception work, which are associated with low decision levels and can end up reducing individuals' productive capacity, consequently leading to a loss of motivation or of previously gained skills. Finally, the upper left quadrant is related to low demand or low-strain work, which has low demand and high control. Despite permitting relaxation, activities in this work modality tend to be uninteresting and represent experiences that can cause some risk of disease due to psychological stress, as the associated control usually is not used (Karasek \& Theorell, 1990). In summary, high and low demand jobs offer greater risks of physical and psychological diseases.

As the decision latitude often depended on different relationships (with colleagues, supervisors and clients) the individuals frequently established in their workplace, Karasek and Theorell (1990) proposed the expansion of the original model. In that sense, they added a new dimension to the model: social support, which involves the socio-affective relationships, that is, the relationships expressed in the work environment, which are important to maintain the health and wellbeing and to gain new knowledge.

After the inclusion of social support, the model was named the demand-control-support model. Hence, it is postulated that overload and psychological demands or pressures, combined with low decision power and lack of social support, can mediate disequilibria in physical and mental health, consequently arousing stress reactions.

In the job context, two psychological reactions to stress that have frequently been studied are job dissatisfaction and depression. Job dissatisfaction is a subjective construct characterized by negative feelings towards work, which can be provoked by stressing situations. Depression as a result of occupational stress can be identified by a reduced capacity to solve problems or cope with challenges at work, by the loss of motivation, by the sadness or by feelings of helplessness, which are almost always associated with decreased productivity (Karasek, 1979). Psychosomatic problems associated with headache, nausea, vomiting, back pain, digestive difficulties, muscle aches, low immunity, hypertension, cardiovascular diseases and breathing and sleep difficulties, among others, have also been adopted as stress manifestations in research (Cooper et al., 2001; Karasek \& Theorell, 1990).

\section{Stress in Lawyers}

According to Elwork (2007), lawyers' daily work is marked by the constant pressure of deadlines and decisions; the increasing complexity of laws and legal procedures; the need for constant updates about the jurisprudence, doctrine and laws; the high level of demands from clients; the competition with colleagues; the negative feeling towards other lawyers; the opposition of other lawyers and judges; the long work hours; the distancing from the family due to work; the practice of an eminently intellectual activity; the constant contact with conflicts, aggressions and accusations; the need to cope with personal difficulties; the disappointments deriving from accusations and contradictory trials that promote aggression and by the need to maintain an aggressive, analytic, critical, rational and perfectionist profile. In addition, they live with the fact that they have little or no time to practice exercises, 
to maintain appropriate eating habits and to develop leisure activities or go on holiday.

This context has strongly affected the lawyers' mental health, making them experience increasing stress levels. In that sense, some empirical studies have indicated high levels of depression and alcohol use among lawyers. In a study that involved 1184 lawyers from Washington, for example, Benjamin, Darling and Sales (1990) found that 19\% of the sample displayed high depression levels, compared with three to nine percent in the general population of industrialized countries, while $18 \%$ presented alcohol abuse problems, against a $10 \%$ prevalence rate of alcohol abuse among North American adults. In addition, it was observed that the lawyers with longer professional experience seemed to be more susceptible to alcohol abuse-related problems.

In another study, Eaton, Anthony, Mandel and Garrison (1990) attempted to identify, in a set of 104 occupations, those professionals with the highest prevalence rates of depressive disorder. The results revealed that workers in three professions - lawyer, teacher and secretary - reached the DIS/DSM-III criterion for the diagnosis of depressive disorder, besides significantly higher prevalence rates of major depressive disorder when compared to the other workers. Using a sample of two groups of lawyers who were taking graduate programs in Arizona (802 individuals) and Washington (1184 individuals), Beck, Sales and Benjamin (1996) found that male and older lawyers presented more alcohol-related problems. Also, a much higher percentage of lawyers than would be expected in the normal population reported problems related to alcohol use.

Other studies have revealed that the work overload represents an important source of stress in lawyers. In that sense, Wallace (1999) investigated, among other objectives, whether the work overload affected the work $\mathrm{x}$ family conflicts based on time (lack of time for family and friends), as well as the gender differences in these variables. The sample included 512 male and female lawyers, out of 1300 active professionals in a city in Western Canada. The analysis of the results showed that men reported working significantly more hours than women, who affirmed having a significantly heavier work overload than men. It was also verified that the work overload was the most important and significant positive predictor of work-family conflicts.

In another study, Wallace (2002) explored the personal, family and professional life demands in a sample of 121 Canadian lawyers, as well as the strategies they used to deal with these demands. The collected data revealed that the participants set their professional activity as their primary priority all the time, which is why they used to work an average 50 hours per week, which generally involved nights and weekends. In their opinion, this overload represented one of the main stressors in their lives, making them feel dissatisfied with the fact that this situation does not allow them to spend enough time on leisure and with their family. To cope with the stress the profession causes, the strategies that were generally used were the search for social support from family and friends or working at home. Social support from the family and friends also revealed to be a buffering or inhibiting factor of stress symptoms in the study by Beck et al. (1996), cited earlier.

According to Daicoff (2008), however, there are few studies that analyze stress in lawyers, especially concerning the impact of the set of different factors in the job environment on stress manifestations. On the other hand, none of these studies have been developed with Brazilian samples, as Brazilian occupational stress studies have privileged the education (Codo, 2000) and health professions (Stacciarini \& Tróccoli, 2002), or have been limited to samples of college students (Bondan \& Bardagi, 2008) or only to descriptions of stress indexes in different types of samples (Sadir, Bignotto, \& Lipp, 2010). Therefore, additional studies are justified, which can contribute to a further understanding of the risk factors that influence the mental health of lawyers, through the use of studies that adopt multivariate analyses and can thus investigate the impact of the set of different stressors on several indicators of this phenomenon. Based on these considerations, the objective in this study was to analyze the predictive power of seven stressors (decision latitude, psychological demands at work, physical demands at work, relationships with clients, job insecurity, social support from colleagues and ergonomic stressors) on depression, job dissatisfaction and psychosomatic problems in Brazilian lawyers, using the model by Karasek and Theorell (1990) as a reference framework.

\section{Method}

\section{Participants}

In this research, a convenience sample was used and the only inclusion criterion was related to the fact that participants should be lawyers with at least one year of professional experience. The final sample included 702 Brazilian lawyers, $53.7 \%$ male. In the group of participants, $34.9 \%$ were between 20 and 30 and $31.3 \%$ between 31 and 40 years of age. The majority lived in the Brazilian Southeast (84.3\%) and $46 \%$ were married. These lawyers mainly possessed between one and five years $(45.8 \%)$ and between six and ten years (23.5\%) of professional experience. As regards the type of job contract, a large part was self-employed (64.2\%). Concerning the activity areas, only $31.2 \%$ worked in a single area, while the remainder was active in more than one area at the same time. The three most cited areas were civil law $(32.5 \%)$, family law (18.3\%) and labor law (16.9\%).

\section{Instrument}

The data were collected using the Job Content Questionnaire (JCQ), developed by Karasek (1985) and adapted for use in Brazilian samples by the authors of this study. The questionnaire is self-explanatory and is aimed 
at measuring the psychological and social structures of job situations and reactions to them. The part of the questionnaire related to the employment situation demands (stressors) consists of seven scales, which are:

1. Decision latitude - consists of eight items, related to the extent to which individuals use their skills and degree of decision authority, that is, the extent to which the individual has the freedom to make decisions and influence the outcomes and the work groups. Its Cronbach's alpha was .72.

2. Psychological demands of work - the eight items in this scale relate to the levels of psychological demands the workers are confronted with in their job context, with a Cronbach's alpha of .78.

3. Physical demands of work - associated with the use of physical effort to accomplish job activities, including three items, with a Cronbach's alpha of .78.

4. Job insecurity - the five items are related to the degree of stability on the job, that is, the extent to which the job permits career promotions or can lead to unemployment. Its Cronbach's alpha was .69.

5. Relationships with clients - including six items, the scale refers to the problems deriving from contacts with clients, with a Cronbach's alpha of .66.

6. Ergonomic stressors - the three items in this scale are associated with ergonomically uncomfortable positions that characterize certain professional activities. Its Cronbach's alpha was .73.

7. Social support from colleagues - includes aspects related to social and emotional integration, as well as trust and support received from colleagues in the accomplishment of professional tasks. The scale consists of six items, with a Cronbach's alpha of .84.

As regards the reactions to stress, three of the scales Karasek (1985) added to the JCQ were included, which measured:

8. Job dissatisfaction - consists of five items, to be answered on three-point scales, ranging from very dissatisfied (1) to very satisfied (3), from no (1) to I recommend (3), from I would certainly choose (1) to definitely not (3), from very probably (1) to no chance (3) or from yes (1) to no (3). Its Cronbach's alpha was .74.

9. Depression - the eight items in this scale are answered on seven-point scales, whose extreme ends contain a pair of opposite words, related, respectively, to a positive feeling (1) and to a negative feeling (7) towards life. Its Cronbach's alpha was .90 .

10. Psychosomatic problems - consists of eight items, which should be answered on four-point scales, ranging from frequently (1) to never (4). The Cronbach's alpha of the scale was .80 .

\section{Procedure}

Data collection. The questionnaire to collect the data was made available on a site specifically created for this end, between February and June 2010, and largely disseminated by different professional entities of Brazilian lawyers. In that sense, initially, the Brazilian Bar Association (OAB), Rio de Janeiro (RJ) department, was contacted, which disseminated the research and advised the lawyers to access the specific website. Some days later, the news was posted as a banner on the homepage of the OAB/RJ site, so that the research could be accessed directly through the banner, which remained available until the end of the data collection period. The Federal Bar Association also published a news about the research on its website. As the news posted on the federal $\mathrm{OAB}$ website is highlighted in all regional departments, the research also ended up being disseminated on the websites of the departments of Bahia, Espírito Santo, Minas Gerais, São Paulo, Paraná and Goiás. It was also disseminated in a paper by the general secretary of the Escola Superior de Advocacia do Pará.

Upon accessing the website, the participants were confronted with a first screen that contained information about the research objective, the fact that only lawyers active in the profession for at least one year should answer, the institution where it was developed, the completion form, the responsible researcher and contact information. The participants were also informed that, by answering the research, they agreed with the terms of the informed consent form. Next, the participants had to click on the link "participate in the research", located on the right-hand side of the screen, to open the actual questionnaire. That page gave access to all questions with the help of the scroll bar. At the end of the questionnaire, the participants had to click the button "send". At that moment, they were informed, in case any questions had been left blank, that they should revise the questionnaire to identify the parts marked in red, which indicated blank questions. After answering all questions, the questionnaire was immediately sent and the participants received a message acknowledging their participation.

Data analysis. The data were analyzed through descriptive and correlational analyses. In that sense, initially, the mean scores for each individual scale were calculated. Next, the correlations among the different scales were calculated and the assumptions needed to undertake multiple regression analyses were examined. Then, three hierarchical multiple linear regression analyses were performed, that is, one for each of the dependent variable (job dissatisfaction, depression and psychosomatic problems). In all of them, in the first model, for the sake of control, the sociodemographic variables sex (as a dummy variable, with male $=0$ and female $=1$ ), age, length of professional experience and type of job contract (self-employed, hired, hired in a law firm and self-employed, hired in a company and self-employed) were included. In the second model, the seven stressors (decision latitude, psychological demands at work, physical demands at work, relationships with clients, social support from colleagues, job insecurity and ergonomic stressors) were added. 


\section{Ethical Considerations}

Approval for the research project was obtained from the Research Ethics Committee at Universidade Salgado de Oliveira, before the start of data collection, registered under protocol no. $128 / 2009$.

\section{Results}

The means and standard deviations of the scales and the correlation coefficients are displayed in Table 1. Adopting job dissatisfaction as the criterion variable, it was observed that $5 \%$ of the variance in that variable $\left(R^{2}=.05, F_{(4,696)}=9.51\right.$; $p<.001)$ was explained by the set of variables included in the first model. Among these, only the age variable was significant. The second model resulted in an additional 34\% $\left(R^{2}=.34 ; F_{(7.689)}=55.04 ; p<.001\right)$ of the variance, with six out of 11 predictive variables contributing to explain the criterion variable. In that sense, the final model explained $39 \%$ of job dissatisfaction and indicated that the length of professional experience, the psychological demands at work and job insecurity served as positive and significant predictors of this criterion variable, while age, decision latitude and social support were negative and significant predictors (Table2).

Table 1

Means, Standard Deviations and Correlations Between the Stressors and Reactions to Stress

\begin{tabular}{|c|c|c|c|c|c|c|c|c|c|c|c|}
\hline & $M$ & $S D$ & 1 & 2 & 3 & 4 & 5 & 6 & 7 & 8 & 9 \\
\hline 1 & 3.11 & .47 & - & & & & & & & & \\
\hline 2 & 3.16 & .45 & -.01 & - & & & & & & & \\
\hline 3 & 2.65 & .63 & $.25 * *$ & $-.13^{*}$ & - & & & & & & \\
\hline 4 & 2.03 & .70 & $-.11 * *$ & $.22 * *$ & $-.14 * *$ & - & & & & & \\
\hline 5 & 3.07 & .42 & $.32 * *$ & $.17 * *$ & .03 & .02 & - & & & & \\
\hline 6 & 2.22 & .61 & $-.39 * *$ & $.11 * *$ & $-.38 * *$ & $.27 * *$ & $-.22 * *$ & - & & & \\
\hline 7 & 3.08 & .63 & $-.09 *$ & $.42 * *$ & $-.22 * *$ & $.29 * *$ & $.09^{*}$ & $.21 * *$ & - & & \\
\hline 8 & 1.98 & .50 & $-.38 * *$ & $.21 * *$ & $-.34 * *$ & $.20 * *$ & $-.13 * *$ & $.54 * *$ & $.20 * *$ & - & \\
\hline 9 & 3.27 & 1.37 & $-.34 * *$ & $.22 * *$ & $-.39 * *$ & $.13^{* *}$ & $-.09 *$ & $.44 * *$ & $.27^{* *}$ & $.60 * *$ & - \\
\hline 10 & 2.86 & .59 & $-.12 * *$ & $.38 * *$ & $-.26 * *$ & $.26^{* *}$ & .06 & $.27 * *$ & $.45^{* *}$ & $.31 * *$ & $.39 * *$ \\
\hline
\end{tabular}

Note. 1 = Decision latitude; 2 = Psychological demands at work; 3 = Social support from colleagues; $4=$ Physical demands at work; $5=$ Relationships with clients; $6=$ Job insecurity; $7=$ Ergonomic stressors; $8=$ Job dissatisfaction; $9=$ Depression; $10=$ Psychosomatic problems. ${ }^{*} p<.05 .{ }^{* *} p<.01$.

Table 2

Results of Hierarchical Multiple Regression Analyses of Stressors on Reactions to Stress

\begin{tabular}{|c|c|c|c|}
\hline Variables & $\begin{array}{c}\text { Job dissatisfaction } \\
\beta \\
\end{array}$ & $\begin{array}{c}\text { Depression } \\
\beta \\
\end{array}$ & $\begin{array}{c}\text { Psychosomatic problems } \\
\beta\end{array}$ \\
\hline \multicolumn{4}{|l|}{ Model 1} \\
\hline Age & $-.25 * * *$ & -.08 & -.03 \\
\hline Gender & .07 & .07 & $.15 * * *$ \\
\hline Professional experience & .08 & .05 & .02 \\
\hline Type of job contract & .05 & .03 & .04 \\
\hline \multicolumn{4}{|l|}{ Model 2} \\
\hline Age & $-.23 * * *$ & -.07 & -.03 \\
\hline Gender & .02 & .02 & $.11 * *$ \\
\hline Professional experience & $.10^{*}$ & .08 & .05 \\
\hline Type of job contract & -.01 & -.02 & .02 \\
\hline Decision latitude & $-.18 * * *$ & $-.19 * * *$ & -.01 \\
\hline Psychological demands at work & $.11 * *$ & $.12 * *$ & $.20 * * *$ \\
\hline Social support from colleagues & $-.13 * * *$ & $-.21 * * *$ & $-.11 * *$ \\
\hline Physical demands at work & .03 & -.05 & .07 \\
\hline Relationships with clients & .00 & .00 & .04 \\
\hline Job insecurity & $.39 * * *$ & $.26^{* * *}$ & $.12 * *$ \\
\hline Ergonomic stressors & .02 & $.12 * *$ & $.29 * * *$ \\
\hline
\end{tabular}
${ }^{*} p<.05 .{ }^{* *} p<.01 . * * * p<.001$.

In the prediction of depression, the first group of variables included in the regression equation was responsible for only $1 \%$ of the variance in the criterion variable and was not significant. Adding the seven stressors represented a $31 \%$ addition in the variance of the dependent variable $\left(R_{\Delta}^{2}=.31 ; F_{(7.689)}=44.04 ; p<.001\right)$, with five of 
the predictive variables contributing to explain depression. Thus, the final model explained $32 \%$ of the depression, demonstrating that the psychological demands of work, job insecurity and ergonomic stressors were positive and significant predictors of this criterion variable, while decision latitude and social support served as negative and significant predictors (Table 2).

In the hierarchical multiple linear regression analysis that adopted psychosomatic problems as the criterion variable, the first model explained $3 \%$ of the variance $\left(R^{2}=.03 ; F_{(4.696)}=4.57 ; p<.01\right)$, with sex as the sole significant predictive variable. The inclusion of the stressors in the equation resulted in an additional $28 \%$ in the variance of the dependent variable $\left(R_{\Delta}^{2}=.28 ; F_{(7.689)}=40.30 ; p<.001\right)$. Hence, the final model explained $31 \%$ of the psychosomatic problems, with sex, psychological demands at work, job insecurity and ergonomic stressors serving as positive and significant predictors. Social support from colleagues, in turn, was a negative and significant predictor of this criterion variable (Table 2).

\section{Discussion}

The objective in this study was to analyze the predictive power of seven stressors (decision latitude, psychological demands at work, physical demands at work, relationships with clients, job insecurity, social support from colleagues and ergonomic stressors) for depression, job dissatisfaction and psychosomatic problems in Brazilian lawyers, based on the model by Karasek and Theorell (1990). The results evidenced that decision latitude served as a negative and significant predictor of job dissatisfaction and depression. Hence, it was verified that the lawyers who can use their skills more and possess greater decision power tend to feel less dissatisfied with their work and less depressed. This evidence empirically supports the assertions of Karasek (1979) about the fact that the degree of control or decision latitude represents one of the main triggers of occupational stress. Hence, according to this author, when people have the individual freedom to make decisions and influence the outcomes and work groups, they can act on the demands they are confronted with and, consequently, alter the harmful effects they provoke in their physical and mental health. Similarly, Cooper et al. (2001) emphasize that control over their work allows individuals to interpret the stressful stimuli, that is, to identify and control them, which positively affects their psychological health by reducing their anxiety and depression.

The psychological demands at work also showed to be an important stress predictor, as this characteristic positive and significantly predicts job dissatisfaction, depression and psychosomatic problems. In other words, the evidences demonstrated that the lawyers who experience excessive job demands related to the work overload and frenetic rhythm, among other factors, tend to feel more dissatisfied with work and more depressed, besides experiencing greater psychosomatic problems. These results are in accordance with Wallace's findings (1999) in Canadian lawyers, observing that the work overload was the most important positive and significant predictor of work-family conflicts. In a further research, also involving Canadian lawyers, Wallace (2002) again found that, according to the study participants, the work overload acted as one of the main stressors in their lives, making them feel dissatisfied because this situation does not allow them to spend enough time on leisure and family, which may be one of the reasons why the psychological demands at work acted as one of the main positive predictors of stress in this sample of Brazilian lawyers as well.

According to Karasek and Theorell (1990), not all psychological requirements or demands can affect the individuals' physical and emotional condition, as only those demands they perceive as psychologically heavy produce this effect. Considering that, in this study, the psychological demands affected aspects associated with the lawyers' physical and psychological health, it can be supposed that, in this sample, these demands were perceived as psychologically heavy.

Also in line with Karasek (1979), psychological demand and control are characterized as independent dimensions, both ranging from low to high, creating four different work situation categories: high-strain work (high demand and low control); active work (high demand and high control); passive work (low demand and low control) and low-strain work (low demand and high control). As the mean scores on the decision latitude and psychological demands at work scales were much higher than the medians of these scales, it can be affirmed that, in this sample, legal work was a type of active work. This type of work tends to make individuals more motivated, but can therefore also lead to emotional exhaustion. This finding can be considered yet another piece of evidence that supports the outcomes about the interrelations between decision latitude and the psychological demands at work on the one hand and the different stressors on the other.

Another result that stands out relates to the fact that social support showed to be a powerful stress predictor, as it contributed negative and significantly to the prediction of job dissatisfaction, depression and psychosomatic problems. Hence, it was verified that lawyers with good social and emotional integration in their work environment, that is, who relate with colleagues they trust and from whom they receive professional and emotional support, tend to feel less dissatisfied with their work and less depressed, besides experiencing less psychosomatic problems. In a way, these data are in accordance with earlier results by Beck et al. (1996), showing that social support from family and friends served as a buffer of stress symptoms in North American students; and with data by Wallace (2002), who observed in a study of Canadian lawyers that, in order to cope with their occupational stress, these individuals tended to seek social 
support from family and friends. Although family support constituted a stress prevention factor in these studies, the present data can be considered an extension of these findings, showing that not only family support, but also support from colleagues has the same function of mitigating the stress symptoms the lawyers tend to experience.

Although not included in Karasek's original demandcontrol model (1979), social support was added in a later stage, because Karasek and Theorell (1990) concluded that, sometimes, the decision latitude depended on the relationships the individuals established at their workplace. In other words, according to those authors, the lack of social support, in combination with the psychological demands and low decision power, could act as mediators of disequilibria in physical and mental health, and consequently, occupational stress, in accordance with the present data.

Another stressor that should be emphasized is job insecurity, characteristic of the job situations not included in Karasek and Theorell's (1990) original model, but considered as one of the dimensions of the research model adopted here. This dimension also revealed to act as a powerful stress predictor, in function of its positive and significant contribution to the prediction of job dissatisfaction, depression and psychosomatic problems. Thus, it was verified that the lawyers who perceive their profession as unstable and without opportunities for professional ascent tend to feel more dissatisfied with their work and more depressed, besides experiencing further psychosomatic problems. These data empirically sustain the model by Cooper et al. (2001), which puts forward job insecurity as one of the sources of occupational stress. Therefore, according to those authors, when the professionals feel insecure about their job, profession or function, they tend to issue physiological, psychological and behavioral reactions to stress.

The ergonomic stressors are not considered either in Karasek and Theorell's original model, but were part of the current research model and contributed to explain depression and psychosomatic problems. Hence, it was observed that, when the lawyers are exposed to ergonomically uncomfortable demands, they tend to feel more depressed and experience more psychosomatic problems. These results also represent empirical evidence that supports the theoretical model by Cooper et al. (2001), according to which certain factors intrinsic to work, such as physical and environmental demands, are characterized as stressors capable of changing individuals' neurological and psychological functioning.

It was also verified that age acts as a negative and significant predictor of job dissatisfaction, demonstrating that older lawyers feel less dissatisfied with their work. This evidence is consistent with Daicoff (2004), according to whom older lawyers show to be more satisfied with the profession, in view of their financially more stable career.

Another result that should be emphasized relates to the fact that the length of professional experience served as a positive predictor of job dissatisfaction, signaling that more experienced lawyers were more dissatisfied with their work. This result should be considered with caution though, as the correlation between the length of professional experience and job dissatisfaction was negative. In addition, in the first regression model that used job dissatisfaction as the criterion variable, the length of professional experience was not characterized as a significant predictor. On the other hand, in view of the strong correlation between age and length of professional experience, the later may have acted as a suppressor variable of the age effect on job dissatisfaction and not as a true predictor of this criterion variable.

Finally, the positive and significant predictive effect of sex on psychosomatic problems should be underlined, showing that women tended to experience more psychosomatic problems than men. One possible explanation for this result is that, according to Wallace (1999), female lawyers tend to feel more stressed at work because the feelings of lack of time for the family affect them more, as the work absorbs too many hours per week.

\section{Conclusions}

Based on these results, some strategies can be suggested as a way to reduce the harmful effects of stressors and reinforcing the positive effects. In that sense, presenting coping strategies that make the lawyers reduce the stress levels, through training that induces them to practice sports, to use relaxation techniques and to cognitively reconfigure stress situations, is one measure that can help them to reduce their daily stress. When appropriately applied, such techniques tend to be capable of making these professionals develop cognitive and behavioral resources that permit them to manage the occupational stress they tend to be exposed to (Daicoff, 2012).

In addition, these results can also be adopted for strategic decision making in professional entities and colleges. To give an example, law courses could include psychological preparation for professional practice in their curricula, addressing the main stressors lawyers tend to be exposed to, as well as the main coping strategies that can be adopted to deal with them, as Peterson and Peterson (2009) have suggested.

Also, future research can further elaborate these research results. It would be interesting for additional studies to consider the impact of individual factors, such as personality traits, on the different occupational stress reactions. On the other hand, the impact of stress on the lawyers' career and family should also be investigated further. These studies can undoubtedly contribute to further research about stress in lawyers, especially regarding its individual determinants and consequences for individuals, families, clients and society in general.

Finally, the limitations of this research should be highlighted. The fact that it was only undertaken virtually and worked with a non-probabilistic convenience sample limits the possibilities to generalize the results. In addition, 
although the instructions of the data collection questionnaire emphasize that it should only be completed by lawyers who had been active in the profession for at least a year, it may also have been completed by people who did not comply with these criteria, as this aspect could not be controlled more effectively, as the data were only collected through virtually available electronic forms. Anyway, the research is important in practical and theoretical terms, by focusing on some of the antecedents and consequences of occupational stress in lawyers and demonstrating the feasibility of using the model by Karasek and Theorell (1990) in studies about stress in self-employed professionals.

\section{References}

Beck, C. J. A., Sales, B. D., \& Benjamin, G. A. H. (1996). Lawyer distress: Alcohol-related problems and other psychological concerns among a sample of practicing lawyers. Journal of Law and Health, 10(1), 1-60.

Benjamin, G. A. H., Darling, E. L., \& Sales, B. (1990). The prevalence of depression, alcohol abuse, and cocaine among United States lawyers. International Journal of Law and Psychiatry, 13(3), 233-246. doi:10.1016/01602527(90)90019-Y

Bondan, A. P., \& Bardagi, M. P. (2008). Comprometimento profissional e estressores percebidos por graduandos regulares e tecnológicos. Paidéia (Ribeirão Preto), 18(41), 581-590. doi:10.1590/S0103-863X2008000300013

Codo, W. (Coord.). (2000). Educação: Carinho e trabalho (2nd ed.).Petrópolis, RJ: Vozes.

Cooper, C. L., Dewe, P. J., \& O’Driscoll, M. P. (2001). Organizational stress: A review and a critique of theory, research, and applications. Thousand Oaks, CA: Sage.

Daicoff, S. S. (2004). Lawyer, know thyself: A psychological analysis of personality strengths and weaknesses. Washington, DC: American Psychological Association.

Daicoff, S. S. (2008). Lawyer, be thyself: An empirical investigation of the relationship between the ethic of care, the feeling decision making preference, and lawyer wellbeing. The Virginia Journal of Social Policy \& the Law, 16(1), 87-140.

Daicoff, S. S. (2012). Expanding the lawyer's toolkit of skills and competencies: Synthesizing leadership, professionalism, emotional intelligence, conflict resolution, and comprehensive law. Santa Clara Law Review, 52(3), 795-874.

Eaton, W. W., Anthony, J. C., Mandel, W., \& Garrison, R. (1990). Occupations and the prevalence of major depressive disorder. Journal of Occupational Medicine, 32(11), 1079-1087.

Elwork, A. (2007). Stress management for lawyers: How to increase personal \& professional satisfaction in the law (3rd ed.). North Wales, PA:Vorkell Group.

Karasek, R. A. (1979). Job demands, job decision latitude, and mental strain: Implications for job redesign. Administrative Science Quarterly, 24(2), 285-308.
Karasek, R. A. (1985). Job content questionnaire and user's guide. Lowell, MA: University of Massachusetts Lowell, Department of Work Environment.

Karasek, R., \& Theorell, T. (1990). Healthy work: Stress, productivity, and the reconstruction of working life. New York, NY: Basic Books.

Peterson, T. D., \& Peterson, E. W. (2009). Stemming the tide of law student depression: What law schools need to learn from the science of positive psychology. Yale Journal of Health Policy, Law, and Ethics, 9(2), 357-434.

Sadir, M. A., Bignotto, M. M., \& Lipp, M. E. N. (2010). Stress e qualidade de vida: Influência de algumas variáveis pessoais. Paidéia (Ribeirão Preto), 20(45), 73-81. doi:10.1590/S0103-863X2010000100010

Stacciarini, J. M. R., \& Tróccoli, B. (2002). Estresse ocupacional. In A. M. Mendes, L. O. Borges, \& M. C. Ferreira (Eds.), Trabalho em transição, saúde em risco (pp. 185-205). Brasília, DF: Universidade de Brasília.

Wallace, J. E. (1999). Work to non-work conflict among married male and female lawyers. Journal of Organizational Behaviour, 20(6), 797-816. doi:10.1002/(SICI)1099-1379(199911)20:6<797::AIDJOB942>3.0.CO;2-D

Wallace, J. E. (2002). Juggling it all: Exploring lawyer's work, home, and family demands and coping strategies: Report of stage on findings. Newton, PA: Law School Admission Council.

Maria de Fátima Antunes Alves Costa holds a M.Sc. from the Graduate Program in Psychology of the Universidade Salgado de Oliveira.

Maria Cristina Ferreira is a Full Professor from the Graduate Program in Psychology of the Universidade Salgado de Oliveira.

Received: Nov. $30^{\text {th }}, 2012$ $1^{\text {st }}$ Revision: Jul. $11^{\text {th }}, 2013$ Approved: Jan. $15^{\text {th }}, 2014$

How to cite this article:

Costa, M. F. A. A., \& Ferreira, M. C. (2014). Sources and reactions to stress in Brazilian lawyers. Paidéia (Ribeirão Preto), 24(57), 49-56. doi:10.1590/1982-43272457201407 